\title{
The animal-care regulatory system is a sham
}

\author{
Inspectors often overrate an experiment's value and underestimate the pain it causes.
}

Sir — Your News story "Britain seeks compromise on animal research" (Nature 428,882 ; 2004) focuses on the UK government's proposals to increase investment in non-animal research as a means of addressing public concern with the scientific and ethical validity of animal experimentation.

Although such a policy may have some long-term effect in reducing the level of suffering experienced by animals and producing better research methods, there are other steps that could be taken immediately to address problems with the regulatory framework surrounding animal research.

Your passing reference to the overwhelming lack of trust in the current regulatory regime hits the nail on the head. The number of government inspectors is tiny in comparison with the scale of research, and the majority of those inspectors have backgrounds in animal experimentation.

Work by our campaigning group, Uncaged, has shown that, instead of acting as neutral arbiters, inspectors often share the viewpoint of animal researchers. When granting licences, they seem to underestimate animal suffering, and/or overestimate the usefulness of the research.

Pig-to-primate xenotransplantation research conducted by Imutran at the Huntingdon Life Sciences laboratories in Cambridge, between 1994 and 2000, provides a particularly stark example. Leaked confidential documents published online by Uncaged in April 2003 (see www.xenodiaries.org/evidence.htm), following legal battles with Imutran, reveal that procedures leading to the collapse and death of higher primates were classified by
Home Office inspectors as of merely 'moderate' severity - despite the government's stated policy that these procedures should be classified as 'substantial' or 'severe'.

Our legal battle to publish the inside story of this research was won on the basis of our claim that the documents reveal the Home Office's failure to enforce its own rules. Yet there are no constitutional mechanisms for ensuring accountability, and the government continues to ignore a call by 153 members of parliament for an independent inquiry, as reported in The Guardian newspaper on 11 November 2003.

The public is absolutely correct to distrust our sham of a 'regulatory' system. Dan Lyons

Uncaged Campaigns, 9 Bailey Lane, Sheffield S1 4EG, UK

\section{Label of 'autism' could hold back gifted children}

Sir - As a person with autism, I would like to respond to the ongoing discussion, by Allan Snyder (Nature 428, 470-471; 2004) and Oliver Sacks (Nature 429, 241; 2004), about the links between autism and genius.

In my book Thinking in Pictures (Doubleday, New York, 1995) I was one of the first people to suggest that Einstein had traits of an adult with mild autism. He had no speech until the age of three. The statement I mistakenly attributed to Oliver Sacks was from Swedish psychiatrist Christopher Gillberg, who wondered whether or not the composer Béla Bartók or the philosopher Ludwig Wittgenstein may have been autistic (An Anthropologist on Mars, Knopf, New York, 1995, p 295). Sacks described Gillberg as "one of the finest clinical observers of autism", and he seemed to agree with the above statement.

I agree with Oliver Sacks that the terms autism and Asperger's syndrome are overused. I give talks at many autism conferences. When the milder diagnosis of Asperger's syndrome became popular in the 1990s I started seeing many intellectually gifted children at these conferences. I told one mother that, before Asperger's syndrome became widely accepted, her child would have received a label of 'intellectually gifted'.

In my work I have observed many engineers and scientists who seem to have mild autism or Asperger's traits. One of my great concerns is that a child diagnosed with Asperger's or mild autism will be held back by the label and not have their talents (scientific or otherwise) developed. Temple Grandin Department of Animal Science, Colorado State University, Fort Collins, Colorado 80523, USA

\section{Keeping a clear head on effects of illicit drugs}

Sir - It is surprisingly hard to find a levelheaded, fact-based discussion of issues related to illicit drugs, as is unfortunately illustrated by your recent Editorial "Think harder about ecstasy" and News Feature "The ups and downs of ecstasy" about MDMA or 'ecstasy' (Nature 429, 113 \& 126-128; 2004).

According to your Editorial, "MDMA can cause psychosis, hyperthermia and even death in some people who take the drug recreationally. But there is no research to indicate whether or not this will be a problem in the controlled settings of a clinical trial". This last statement ignores many published phase I studies, including some mentioned in the News Feature.

At least five independent research teams around the world have administered MDMA to more than 200 human subjects in controlled experimental settings, and neither hyperthermia nor psychosis - let alone death — has ever been a problem (see ref. 17 from your News Feature, and others available on request). Increases in body temperature in clinical settings have never exceeded $1{ }^{\circ} \mathrm{C}$, with some studies failing to find any significant increases. Likewise, no cases of psychosis have been reported in controlled clinical trials with pre-screened subjects. Although there may be low levels of individual symptoms (such as thought disturbances or perceptual illusions reported by Vollenweider, myself and colleagues in 1998; see ref. 13 of the News Feature) that can also occur in clinical psychoses, these disappear completely after drug effects have subsided, and they are a far cry from full-blown psychotic states.

It therefore seems misleading for your Editorial to mention only the 12 documented cases of psychosis related to recreational ecstasy use, and for the News Feature to list only "moderate thought disorder" when citing findings from our 1998 study concerning the psychological effects of MDMA. In fact, this study, like others, found that MDMA produced several effects, including positive mood, perceptual alterations and slight anxiety over loss of control that was not psychotic.

Non-selective reporting of factual information is the basis for responsible decisions on drug issues, and is in the interests of both sides of the debate on the therapeutic use of MDMA.

\section{Alex Gamma}

University Hospital of Psychiatry, Lenggstrasse 31, 8029 Zurich, Switzerland

\section{correspondence}

Contributions to Correspondence may be submitted to corres@nature.com. They should be no longer than 500 words, and ideally shorter. 